\title{
Stentless valves versus stented bioprostheses at the aortic position: Midterm results
}

\author{
Sumit Narang, MS, Deepak Kumar Satsangi, MCh, Amit Banerjee, MCh, and Muhammad Abid Geelani, MCh
}

Objective: Our aim was to compare stentless and stented bioprostheses. Clinical outcomes, hemodynamic performance, and postoperative left ventricular mass regression were the principal outcomes assessed.

Methods: Sixty-two patients were recruited for the study. Our protocol was to consider all patients older than 55 years for bioprostheses, and also younger patients were implanted with a bioprosthesis if they wanted to avoid anticoagulation. Patients selected for bioprostheses were randomly assigned to receive stentless (group A) and stented (group B) bioprostheses, depending on the treating unit. Patients in groups A and B were further divided into subgroups I and II based on left ventricular ejection fractions of $50 \%$ or greater and less than $50 \%$, respectively.

Results: At $18 \pm 3$ months postoperatively, the effective orifice area was greater in group A versus group B. Left ventricular ejection fraction, left ventricular mass index, functional class, and mean gradient were similar in patients of subgroup I (left ventricular ejection fraction $>50 \%$ ) from both groups. However, there was a significant difference between all except mean gradient in patients of subgroup II (left ventricular ejection fraction $<50 \%$ ) from both groups. Also, in the patient subgroup implanted with valves of less than $19 \mathrm{~mm}$ (group A, 4 patients; group B, 3 patients), there was a significant difference in left ventricular mass index and mean gradient.

Conclusion: In patients with left ventricular impairment or a small aortic annulus, stentless bioprostheses might allow for greater improvement in left ventricular function postoperatively.

From the Department of Cardiothoracic and Vascular Surgery, G. B. Pant Hospital, Maulana Azad Medical College, New Delhi, India.

Received for publication Dec 30, 2007; revisions received April 28, 2008; accepted for publication June 7, 2008.

Address for reprints: Sumit Narang, MS, Department of Cardiothoracic and Vascular Surgery, G. B. Pant Hospital, Maulana Azad Medical College, New Delhi, India 110002 (E-mail: sumit_narang@yahoo. com).

J Thorac Cardiovasc Surg 2008;136:943-7 $0022-5223 / \$ 34.00$

Copyright $\odot 2008$ by The American Association for Thoracic Surgery

doi:10.1016/j.jtcvs.2008.06.016
A ortic valve replacement (AVR) is the treatment of choice for patients with significant aortic valve disease. This procedure is associated with a low perioperative mortality, minimal morbidity, and good long-term outcomes. Elimination of the sewing ring and stenting of conventional bioprosthetic valves have been proposed to optimize the hemodynamic characteristics of the prosthesis. The intention with these "stentless valves" was to maximize the area for blood flow across the valve, which, in turn, might equate to superior hemodynamic performance through lower postoperative transvalvular gradients. Furthermore, the absence of rigid stents might allow diastolic forces to be more uniformly absorbed within the sinuses of Valsalva, leading to reduced leaflet calcification and improved valve durability. ${ }^{1}$

Their design is postulated to impart characteristics that more closely emulate the normal physiology of the aortic valve and root. It has been further suggested that more favorable hemodynamic performance might lead to enhanced resolution of left ventricular hypertrophy $(\mathrm{LVH}){ }^{2}$ a known potent cause of premature mortality. ${ }^{3,4}$ Modern stented valves have been shown to have excellent hemodynamic characteristics. ${ }^{1,5}$ Previous randomized controlled trials have used a variety of stented and stentless valves, several of which are currently outmoded. ${ }^{6,7}$ Our aim was to conduct a randomized controlled trial to compare widely accepted state-of-the-art stentless and stented prostheses. Clinical outcomes, hemodynamic performance, and postoperative left ventricular mass (LVM) regression were the principal outcomes assessed. 

Abbreviations and Acronyms
$\mathrm{AR}=$ aortic regurgitation
AVR = aortic valve replacement
$\mathrm{EOA}=$ effective orifice area
LVEDD $=$ left ventricular end-diastolic diameter
$\mathrm{LVEF}=$ left ventricular ejection fraction
LVH = left ventricular hypertrophy
$\mathrm{LVM}=$ left ventricular mass
LVMI = left ventricular mass index

\section{Materials and Methods}

Sixty-two patients were recruited for the study. Patients selected for a bioprosthesis were randomly assigned to stentless and stented bioprostheses depending on the treating unit, with all patients in treating unit $\mathrm{A}$ given a stentless bioprosthesis (group $\mathrm{A}, \mathrm{n}=30$ ) and all patients in treating unit $\mathrm{B}$ given a modern stented bioprosthesis (group $\mathrm{B}, \mathrm{n}=32$ ). Patients in groups $\mathrm{A}$ and $\mathrm{B}$ were further divided into subgroups I and II depending on left ventricular ejection fractions (LVEFs) of $50 \%$ or greater and less than $50 \%$, respectively.

All patients older than 55 years were considered for a bioprosthesis. Patients younger than 55 years were implanted with a bioprosthesis if they wanted to avoid anticoagulation. All patients with aortic aneurysms, severely asymmetric aortic roots, annuloaortic ectasia, active aortic valve infection, renal failure requiring dialysis, and requirement for additional cardiac procedures were excluded from the study.

All patients were implanted with valves of $19 \mathrm{~mm}$ or larger. The Freestyle porcine tissue valve (Medtronic, Inc) has been used as a stentless bioprosthetic valve, and the Carpentier-Edwards Perimount Standard aortic valve (Edwards Life Sciences Corp) has been used as a stented bioprosthesis. In patients with an aortic annulus of less than $19 \mathrm{~mm}$, the aortic root enlargement technique (Nicks) was used to implant a 19-mm valve. Patients with very small aortic roots requiring complex root enlargement procedures were excluded. We have accepted the 19-mm valve size because of the smaller average body surface area in our patients.

Stented valves were implanted with the continuous or interrupted suture technique, and stentless valves were implanted with the inclusion cylinder technique.

The inclusion cylinder implantation technique involves a proximal suture line (continuous or interrupted) like the subcoronary technique in a circular plane coursing below the commissures. Generous openings are made by excising the sinuses facing the right and left main coronary ostia. These are then tacked around the ostia, much as a root inclusion Bentall procedure, with continuous 5-0 polypropylene sutures. The aortotomy is then closed in standard fashion after trimming the device top down as necessary to incorporate the closure, making sure that the complete circle of the sinotubular junction is left intact.

Postoperatively, all patients received $75 \mathrm{mg}$ of aspirin as prophylaxis against thromboembolism. Patients were formally anticoagulated only if there were specific indications, such as atrial fibrillation. Clinical and echocardiographic parameters were recorded preoperatively, and functional status and echocardiographic parameters were reevaluated. Mean follow-up was $18 \pm 3$ months
TABLE 1. Demographic profile, clinical characteristics, and echocardiographic parameters

\begin{tabular}{|c|c|c|c|}
\hline & $\begin{array}{l}\text { Group A } \\
(\mathrm{n}=\mathbf{3 0})\end{array}$ & $\begin{array}{l}\text { Group B } \\
(n=32)\end{array}$ & $\begin{array}{c}P \\
\text { value }\end{array}$ \\
\hline Age (y) & $55 \pm 8$ & $56 \pm 10$ & NS \\
\hline \multicolumn{4}{|l|}{ Sex } \\
\hline Male & 22 & 22 & NS \\
\hline Female & 18 & 20 & NS \\
\hline \multicolumn{4}{|l|}{ NYHA class } \\
\hline $\mathrm{I}(\mathrm{A} / \mathrm{B})$ & $2 / 1$ & $2 / 1$ & NS \\
\hline II $(A / B)$ & $8 / 4$ & $7 / 5$ & NS \\
\hline III/IV (A/B) & $9 / 6$ & $10 / 7$ & NS \\
\hline \multicolumn{4}{|l|}{ LVEF } \\
\hline$\geq 50 \%(A)$ & 19 & 19 & NS \\
\hline A & $165 \pm 21$ & $162 \pm 19$ & NS \\
\hline$<50 \%(\mathrm{~B})$ & 11 & 13 & NS \\
\hline $\mathrm{B}$ & $188 \pm 20$ & $187 \pm 24$ & NS \\
\hline \multicolumn{4}{|l|}{$\operatorname{LVMI}\left(\mathrm{g} / \mathrm{m}^{2}\right)$} \\
\hline Ischemic time (min) & $89 \pm 13$ & $57 \pm 10$ & S \\
\hline CPB time (min) & $115 \pm 17$ & $86 \pm 14$ & $S$ \\
\hline $\mathrm{BSA}\left(\mathrm{m}^{2}\right)$ & $1.57 \pm 0.12$ & $1.56 \pm 0.13$ & NS \\
\hline Valve size implanted & $21.3 \pm 1.3$ & $21.5 \pm 1.4$ & NS \\
\hline \multicolumn{4}{|l|}{ Cause } \\
\hline AS & 19 & 22 & NS \\
\hline AR & 11 & 10 & NS \\
\hline LVEDD in AS $(\mathrm{cm})$ & $5.1 \pm 0.8$ & $5.2 \pm 0.7$ & NS \\
\hline LVEDD in AR $(\mathrm{cm})$ & $6.4 \pm 1.1$ & $6.3 \pm 1.1$ & NS \\
\hline
\end{tabular}

$N S$, Not significant $(P>.05)$; NYHA, New York Heart Association; $L V E F$, left ventricular ejection fraction; $L V M I$, left ventricular mass index; $S$, significant $(P \leq .05) ; C P B$, cardiopulmonary bypass; $B S A$, body surface area; $A S$, aortic stenosis; $A R$, aortic regurgitation; $L V E D D$, left ventricular end-diastolic diameter.

for both groups. Echocardiographic parameters recorded were effective orifice area (EOA), LVEF, left ventricular end-diastolic diameter (LVEDD), mean gradient, and left ventricular mass index (LVMI). Functional status was recorded in terms of New York Heart Association functional class.

The protocol of the study was approved by the institutional review board before the start of the study. Informed consent was obtained from each patient before inclusion in the study.

The data have been expressed as means and standard deviations. The Student $t$ test has been used for statistical analysis.

\section{Results}

Preoperative demographic profile, clinical characteristics, and echocardiographic parameters were comparable in both groups (Table 1). Mean valve size implanted was $21.3 \pm$ $1.2 \mathrm{~mm}$ in group A and $21.4 \pm 1.3 \mathrm{~mm}$ in group B. One patient in group A (subgroup II) and 1 patient in group B (subgroup II) died of low cardiac output failure.

The EOA was greater in group A versus that in group B. LVEF, LVMI, mean gradient, and New York Heart Association functional status were similar in patients of subgroup I (LVEF $\geq 50 \%$ ) of both groups (Table 2). However, there 
TABLE 2. Postoperative parameters of patients with LVEFs of $50 \%$ or greater

\begin{tabular}{|c|c|c|c|}
\hline & $\begin{array}{c}\text { Group A } \\
\text { (subgroup I; } \\
\text { n= 19) }\end{array}$ & $\begin{array}{c}\text { Group B } \\
\text { (subgroup I; } \\
\mathbf{n}=\mathbf{1 8} \text { ) }\end{array}$ & $P$ value \\
\hline LVEF (\%) & $61 \pm 5$ & $59 \pm 4$ & $S$ \\
\hline $\mathrm{EOA}\left(\mathrm{cm}^{2}\right)$ & $1.71 \pm 0.12$ & $1.52 \pm 0.12$ & $S$ \\
\hline LVMI $\left(\mathrm{g} / \mathrm{m}^{2}\right)$ & $110 \pm 12$ & $118 \pm 13$ & NS \\
\hline \multicolumn{4}{|l|}{ NYHA class } \\
\hline I & 14 & 14 & NS \\
\hline II & 5 & 4 & NS \\
\hline III/IV & 0 & 0 & NS \\
\hline Mean gradient $(\mathrm{mm} \mathrm{Hg})$ & $9 \pm 3$ & $13 \pm 6$ & NS \\
\hline
\end{tabular}

$L V E F$, Left ventricular ejection fraction; $S$, significant $(P \leq .05) ; E O A$, effective orifice area; $L V M I$, left ventricular mass index; $N S$, not significant $(P>.05)$; NYHA, New York Heart Association.

was a significant difference between all these parameters except mean gradient in patients of subgroup II (LVEF $<50 \%$ ) from both groups (LVEF, 56\% vs 45\%; LVMI, 115 vs $140 \mathrm{~g}$ / $\mathrm{m}^{2}$; and mean gradient, 8 vs $11 \mathrm{~mm} \mathrm{Hg}$ ), with more improvement in functional status of patients of group A (subgroup II) compared with those of group B (subgroup II; Table 3). In the patient subgroup with a small aortic root who were implanted with a 19-mm valve (group A, 4 patients; group B, 3 patients), although the number of patients was much less, there was a significant difference in LVM, EOA, and mean gradient between this subgroup of patients of groups A and B (LVMI, 117 vs $138 \mathrm{~g} / \mathrm{m}^{2}$; mean gradient, 11 vs $25 \mathrm{~mm} \mathrm{Hg}$; and EOA, 1.57 vs $1.34 \mathrm{~cm}^{2}$, respectively), with better functional status in patients of group A (Table 4).

On performing multivariate analysis in patients with poor left ventricular function ( $\mathrm{LVEF}<50 \%$ ), the type of valve im-

TABLE 3. Postoperative parameters of patients with LVEFs of less than $\mathbf{5 0 \%}$

\begin{tabular}{|c|c|c|c|}
\hline & $\begin{array}{c}\text { Group A } \\
\text { (subgroup II; } \\
n=10 \text { ) }\end{array}$ & $\begin{array}{c}\text { Group B } \\
\text { (subgroup II; } \\
n=12 \text { ) }\end{array}$ & $P$ value \\
\hline LVEF preop (\%) & $36 \pm 6$ & $35 \pm 5$ & NS \\
\hline LVEF postop (\%) & $52 \pm 6$ & $43 \pm 5$ & $S$ \\
\hline LVMI $\left(\mathrm{g} / \mathrm{m}^{2}\right)$ & $115 \pm 11$ & $140 \pm 14$ & S \\
\hline \multicolumn{4}{|l|}{ NYHA class } \\
\hline I & 6 & 2 & S \\
\hline II & 3 & 6 & $S$ \\
\hline III/IV & 1 & 2 & NS \\
\hline $\mathrm{EOA}\left(\mathrm{cm}^{2}\right)$ & $1.69 \pm 0.08$ & $1.53 \pm 0.09$ & $S$ \\
\hline Mean gradient $(\mathrm{mm} \mathrm{Hg})$ & $8 \pm 3$ & $11 \pm 3$ & NS \\
\hline
\end{tabular}

$L V E F$, Left ventricular ejection fraction; preop, preoperative; postop, postoperative; $N S$, not significant $(P>.05) ; S$, significant $(P \leq .05) ; L V M I$, left ventricular mass index; NYHA, New York Heart Association; EOA, effective orifice area.
TABLE 4. Postoperative parameters of patients with a small annulus

\begin{tabular}{lcc}
\hline & Group A $(\mathbf{n}=\mathbf{4})$ & Group B $(\mathbf{n}=\mathbf{3})$ \\
\hline EOA $\left(\mathrm{cm}^{2}\right)$ & 1.47 & 1.28 \\
LVMI $\left(\mathrm{g} / \mathrm{m}^{2}\right)$ & 117 & 138 \\
NYHA class & & \\
I & 3 & - \\
II & 1 & 3 \\
III/IV & - & - \\
Mean gradient $(\mathrm{mm} \mathrm{Hg})$ & 11 & 25 \\
LVEF postop $(\%)$ & 61 & 60 \\
\hline
\end{tabular}

EOA, Effective orifice area; $L V M I$, Left ventricular mass index; NYHA, New York Heart Association; $L V E F$, left ventricular ejection fraction; postop, postoperative.

planted and preoperative LVEDD were independent factors for predicting postoperative improvement in left ventricular function and LVM regression. All patients in this group who were implanted with a stentless valve had significantly more improvement in both these parameters postoperatively compared with those who were implanted with stented valves. All patients with aortic insufficiency and an LVEDD of greater than $6.5 \mathrm{~cm}$ had less improvement in both these parameters postoperatively compared with those who had an LVEDD of less than $6.5 \mathrm{~cm}$ preoperatively. Patients with aortic stenosis and an LVEDD of greater than $5.5 \mathrm{~cm}$ had less improvement in both these parameters postoperatively compared with those who had an LVEDD of less than $5.5 \mathrm{~cm}$ preoperatively. Over a mean follow-up of $18 \pm$ months, we have found that none of the patients in either group had moderate or severe atrial regurgitation (AR), and only 2 patients in group A and 2 patients in group B had mild AR.

\section{Discussion}

In population studies LVH has been associated with an increased incidence of sudden death, myocardial infarction, congestive heart failure, and consequently poorer long-term survival than seen in age-matched control subjects. ${ }^{3}$ It has been suggested that enhanced regression of LVH after AVR might translate into clinical benefits. More complete resolution of LVH could lead to improvements in longterm survival. Observational studies have reported that stentless bioprostheses confer hemodynamic advantages after AVR, which might allow for superior regression of LVH and more favorable long-term outcomes in patients operated on for aortic valve disease. ${ }^{1,7}$

Our inability to document any hemodynamic advantages or superior LVM regression after stentless AVR parallels the findings of other recent randomized trials. ${ }^{8-10}$ Newergeneration stented valves have a lower profile and more narrow sewing rings, which produce less impedance to transvalvular flow than older designs. Excellent hemodynamic 
performance of stented prostheses in the aortic position has been documented by a number of investigators. 1,5

It has been inferred that the use of a stentless bioprosthesis might be particularly advantageous in the setting of preoperative ventricular impairment. This is based on the findings of a few investigators who suggest that stentless valves might allow for greater improvement in left ventricular function postoperatively. ${ }^{11-14}$ It has been demonstrated that early after AVR, stentless prostheses allow for a greater and more immediate reduction in left ventricular systolic wall stress. This observation has been correlated with improved ventricular function in the early postoperative period. ${ }^{11-14}$ This difference wanes after 12 months postoperatively, except in patients with left ventricular impairment. Our randomized study seems to substantiate this observation with a difference in LVMI regression, and improvement in functional status between groups A and B at a mean follow-up of $18 \pm 3$ months was statistically significant in patients with left ventricular impairment preoperatively. In patients with reduced ventricular function, this finding might have important implications for long-term outcome. Also, we found that preoperative LVEDD was an independent factor for improvement in left ventricular function and LVM regression in patients with an LVEF of less than 50\%. All patients with AR and an LVEDD of greater than $6.5 \mathrm{~cm}$ had less improvement in both these parameters postoperatively compared with those who had an LVEDD of less than $6.5 \mathrm{~cm}$ preoperatively. Patients with aortic stenosis and an LVEDD of greater than $5.5 \mathrm{~cm}$ had less improvement in both these parameters postoperatively compared with those who had an LVEDD of less than $5.5 \mathrm{~cm}$ preoperatively. This finding is similar to that shown by Tafreshi and colleagues, ${ }^{15}$ who demonstrated end-diastolic dimensions to be an important predictor for persistent postoperative left ventricular dysfunction.

In the present study we have chosen to implant bioprosthetic valves in patients older than 55 years. The age group in our study is younger than that for bioprosthetic valve implantation seen in other studies (ie, $>65$ years age). We have lowered the age limit for implanting a bioprosthetic valve in our study because of the lower average life expectancy in our country.

Our observations suggest that the routine use of stentless bioprostheses over stented valves in all patients on the presumption that they confer hemodynamic advantages is unlikely to be justified. However, in specific patient groups undergoing AVR, stentless valves might provide important benefits. We noted a trend toward improved hemodynamic performance of stentless valves in patients with left ventricular impairment preoperatively and those with smaller aortic annuli. In patients with an annular diameter of less than or equal to $19 \mathrm{~mm}$ who were implanted with a $19-\mathrm{mm}$ valve, the mean systolic gradient was significantly lower in stentless valve recipients, with significantly better functional status at $18 \pm$ months postoperatively. ${ }^{14}$ However, this patient group comprised only a small proportion of our entire study cohort.
In our study patients receiving stentless valves had a significantly greater EOA compared with those with stented valves $18 \pm$ months after AVR. The absence of significant AR in both groups at a mean follow-up of $18 \pm$ months shows durability of both these valve types; however, long-term followup is required to substantiate this finding. Also, this study suggests that patients with huge left ventricular dimensions (LVEDD $>6.5 \mathrm{~cm}$ in severe AR and $>5.5 \mathrm{~cm}$ in severe aortic stenosis) with an LVEF of less than 50\% had less LVM regression and functional improvement after AVR. Hence these patients should undergo operations early before deterioration in LVEF.

In conclusion, both stented and stentless bioprostheses are associated with excellent clinical and hemodynamic outcomes at a mean follow-up of $18 \pm 3$ months. Comparable hemodynamics and LVM regression can be achieved with a newer-generation stented bioprosthesis. In patients with ventricular impairment and those with a small annulus, stentless bioprostheses might allow for greater improvement in left ventricular function and greater improvement in functional class postoperatively. Hence despite increased operative time for implantation of stentless valves, this is the subgroup of patients who were benefited with implantation of a stentless valve. With studies showing long-term durability of stentless valves ${ }^{13}$ and improved outcomes of redo operations, stentless valves can be considered as a first option in younger patients with left ventricular impairment or with a small aortic annulus.

We also conclude that patients with huge left ventricular dimensions should be operated on early before deterioration of left ventricular function to achieve better postoperative results.

We thank Dr Ruchika Narang, MBBS, PhD, for assistance in analyzing data and in the compilation of this manuscript.

\section{References}

1. Le Torneau T, Vincentelli A, Fayad G, Savoye C, Fabre OH, Prat A, et al. Ten-year echocardiographic and clinical follow-up of aortic Carpentier-Edwards pericardial and supraannular prosthesis: a case-match study. Ann Thorac Surg. 2002;74:2010-5.

2. Maselli D, Pizio R, Bruno LP, Di Bella I, De Gasperis C. Left ventricular mass reduction after aortic valve replacement: homografts, stentless and stented valves. Ann Thorac Surg. 1999;67:966-71.

3. Levy D. Clinical significance of left ventricular hypertrophy: insights from the Framingham Study. J Cardiovasc Pharmacol. 1991;17(suppl 2):S1-6.

4. Ghali JK, Liao Y, Simmons B, Castener A, Cao G, Cooper RS. The prognostic role of left ventricular hypertrophy in patients with or without coronary artery disease. Ann Intern Med. 1992;117:831-6.

5. Dellgren G, David TE, Raanani E, Armstrong S, Ivanov J, Rakowski H. Late hemodynamic and clinical outcomes of aortic valve replacement with the Carpentier-Edwards Perimount pericardial bioprosthesis. J Thorac Cardiovasc Surg. 2002;124:146-54.

6. Williams RJ, Muir DF, Pathi V, MacArthur K, Berg GA. Randomized controlled trial of stented and stentless aortic bioprosthesis: hemodynamic performance at 3 years. Semin Thorac Cardiothorac Surg. 1999;11(suppl 1):93-7.

7. Del Rizzo DF, Goldman BS, Christakis GT, David TE. Hemodynamic benefits of the Toronto Stentless Valve. J Thorac Cardiovasc Surg. 1996;112:143-5. 
8. Walther T, Falk V, Langebartels G, Kruger M, Bernhardt U, Diegeler A, et al. Prospectively randomized evaluation of stentless versus conventional biological aortic valves: impact on early regression of left ventricular hypertrophy. Circulation. 1999;100(suppl):II6-10.

9. Doss M, Martens S, Wood JP, Aybek T, Kleine P, Wimmer Greinecker G, et al. Performance of stentless versus stented aortic valve bioprosthesis in the elderly patient: a prospective randomized trial. Eur $J$ Cardiothorac Surg. 2003;23:299-304.

10. Cohen G, Christakis GT, Joyner CD, Morgan CD, Tamariz M, Hanayama N, et al. Are stentless valves hemodynamically superior to stented valves? A prospective randomized trial. Ann Thorac Surg. 2002;73:767-8.

11. Jin XY, Zhong MZ, Gibson DG, Yacoub MH, Pepper JR. Effects of valve substitutes on changes in left ventricular function and hypertrophy after aortic valve replacement. Ann Thorac Surg. 1996;62:683-90.
12. Ali A, Halstead JC, Cafferty F, Sharples I, Rose F, Coulden R, et al. Are stentless valves superior to modern stented valves? A prospective randomized trial. Circulation. 2006;114(suppl):I535-40.

13. Auriemma S, D'Onofrio A, Brunelli M, Magagana P, Paccanaro M, Rulfo F, et al. Long term results of aortic valve replacement with Edwards Prima Plus stentless bioprosthesis: eleven years' follow up. J Heart Valve Dis. 2006;15:691-5.

14. Deleuze PH, Fromes Y, Khoury W, Maribas P, Lemaire S, Bical OM. Eight-year results of freestyle stentless bioprostheses in the aortic position: a single-center study of 500 patients. J Heart Valve Dis. 2006;15: 247-52.

15. Tafreshi RI, Shahmohammadi A, Davari PN. Predictors of left ventricular performance after valve replacement in children and adolescents with chronic aortic regurgitation. Pediatr Cardiol. 2005;26:331-7. 